\title{
Tungsten Oxide Nanoparticles as Corrosion Inhibitor of Stainless Steel in Saline Medium
}

\author{
Haider M. Raheem ${ }^{1}$, Taghried A. Salman ${ }^{1, *}$ \\ ${ }^{1}$ Department of Chemistry, College of Science, Al-Nahrain University, Baghdad, Iraq
}

\begin{tabular}{ll}
\hline Articles Information & Abstract \\
\hline Received: & Tungsten oxide (WO3) nanoparticles at various concentrations of $1.7 \times 10-2$, \\
$20,11,2019$ & $2.5 \times 10-2$ and $3.4 \times 10-2$ M were electrophoretic deposited onto stainless steel \\
Accepted: & surface for corrosion inhibition investigations with respect to concentration as \\
$04,02,2020$ & well as temperature by using potentiostatic polarization technique. Results \\
Published: & obtained show that WO3 nano coating was used as a barrier layer for the \\
01, March, 2020 & corrosion protection of stainless steel in saline solution. The morphology of \\
& nanoparticles was examined using Scanning Electron Microscopy (SEM).The \\
& obtained results indicated that these nanoparticles are good inhibitors. All \\
polarization curves yielded similar behavior pointing to stainless steel corrosion & is controlled by the charge transfer process so that the stainless steel dissolution \\
Keywords: & mechanism does not alter due to the presence of the nanoparticles. Generally, \\
Electrophoretic deposition & increasing the inhibitor concentration and temperatures leads to an increase in \\
Tungsten oxide & the inhibition efficiency. Thermodynamic parameters were calculated, and the \\
Stainless steel & energy of activation data obtained of the corrosion reaction was decreased with \\
Corrosion & an increase of the concentration of nanoparticles. It is likely that the adsorption \\
Saline medium & of WO3NP on the surface of stainless steel was chemical in nature. \\
& \\
\hline
\end{tabular}

DOI: 10.22401/ANJS.23.1.04

*Corresponding author: dr.tag_s@yahoo.com

\section{Introduction}

Electrophoresis was utilized widely in biological, chemical and materials sciences, and bioengineering for the control and preparing of an assortment of natural materials (proteins, cells, and so on.), liquid phase and colloids [1]. In construct, electric field helped electrodeposition, chemical deposition, and electroplating, were utilized for various years in materials science, mechanical materials handling, and slender film applications including valuable metal coatings, composite artistic arrangement, and bio-dynamic materials, different paints and colors. Ongoing exploration [2] enthusiasm for nanoscience and nanotechnology has concentrated on finding easy systems to control materials that truly have demonstrated to be hard to deal with on account of their size. Practically, nanomaterials represent a significant test in their proficient treatment because of their lessened size. Of the large number of accessible systems to control the dissemination of these materials, the electrophoretic deposition (EPD) of nanomaterials seems, by all accounts, to be perfectly appropriate for the distribution and deposition of nanomaterials, giving an effortless, speedy intends to create firmly stuffed movies of nanoparticle, nanotubes, and other nanostructured materials. EPD joins parts of electrophoresis and the interpretation of charged particles, suspended in the medium, because of a surrounding, direct flow of an electric field and dielectrophoresis of the movement of dipolar, polarizable, or charged particles, likewise in arrangement, because of exchanging flow or inclination electric fields leads to precipitation of nanomolecules onto the electrode surface [3]. Tungsten oxide $\left(\mathrm{WO}_{3}\right)$ nanomaterial considered as corrosion inhibitor of metals and alloys due to its advantages such as low cost, low toxicity and easy production [4]. The precipitation of metal and/ or metal oxide nanoparticles composites allowed progress in the field of defensive coatings. Sajjadnejad et al. [5] improved the corrosion 


\title{
Al-Nahrain Journal of Science
}

\author{
ANJS, Vol.23 (1), March, 2020, pp. 27 - 34
}

obstruction of zinc by $\mathrm{TiO}_{2}$ nanoparticles codeposition, while Zeng et al.[6] study the use of $\mathrm{CeO}_{2}$ nanoparticles for improvement of the corrosion attitude of nickel coatings. Hence, there are no research reports in the literature known by the authors where (EPD) has been utilized for the deposition of $\mathrm{WO}_{3}$ nanoparticles as protection films. Stainless steel alloy is an amalgam of iron with at least $10.5 \%$ Chromium. Chromium generated an oxide thin layer on the steel surface known as the 'passive layer'. This layer prevent occurrence of any further corrosion of the surface. Resistance to corrosion increased as the amount of Chromium increased. On the other hand, Steel also contains changeful measures of Manganese Silicon, and Carbon. Various components may be added, for example, molybdenum and nickel to improve other good properties, for example, improving susceptibility and increasing corrosion resistance [7].

This research aimed to performed electrophoretic deposition of tungsten oxide nanoparticles on stainless steel surface as corrosion inhibitor in saline medium. The effect of various concentrations of tungsten oxide nanoparticles and temperature on protective behavior of coated steel in $3.5 \%$ sodium chloride solution was investigated by using Tafel polarization method. SEM images were also employed for investigating of the surface morphology and phase structure of coatings nanoparticles, respectively.

\section{Experimental}

\subsection{Solutions Preparation}

$35 \mathrm{~g}$ of sodium chloride salt of $99.9 \%$ purity, Sigma Aldrich was dissolved one litter of distilled water in order to prepare $3.5 \%$ of $\mathrm{NaCl}$ solution. Tungsten oxide nanoparticles was prepared in different concentrations of $1.7 \times 10^{-2}, 2.5 \times 10^{-2}$ and $3.4 \times 10^{-2} \mathrm{M}$ by adding a measurable quantity of it in $100 \mathrm{~mL}$ of absolute ethanol to prepare emulsion coating solutions and few amount of iodide is added to these solutions in order to increase their conductivity.

\subsection{Electrophoresis Deposition of Emulsion (Coating Samples)}

Electrophoresis deposition of tungsten oxide nanoparticles on stainless steel substrate was carried out by using direct current D.C voltage power supply from 0 to $15 \mathrm{~V}$. A150 ml covered beaker has two slits with a distance of $1 \mathrm{~cm}$ between them and the circuit is used by the $\mathrm{AC}$ meter. Measurement of the current generated between the electrodes. Meanwhile, the stainless steel rode used as inert electrode in deposition process cell and stainless steel specimen is caught by means of tong made of stainless steel. The deposition of specimens occurs at various time and finally, the specimens were thermally dried in an oven at $100{ }^{\circ} \mathrm{C}$ for 2 min. Following the above mentioned EPD, procedure a thick film was coated on stainless steel to ensure a uniform coating of the tungsten oxide nanoparticles film.

\subsection{Electrochemical Consideration}

Electrochemical studies were made using threeelectrode potentiostatic device which respectively, reference (Saturated Calomel), auxiliary (platinum) and working electrode (stainless steel alloy) electrodes. The Wenking M Lab multi-channel system and the SCI-M Lab system for corrosion measurement obtained from Bank ElectronicsIntelligent controls $\mathrm{GmbH}$, Germany 2007 is used as a high tech electrical measuring device. M Lab is powered by Window XP desktop computer. The inhibition efficiency (\% $\mathrm{IE}$ ) of tungsten oxide in the inhibition of stainless steel in $3.5 \%$ of sodium chloride solution was calculated from relation[8]:

$$
\text { IE }(\%)=\left[\left(i_{\text {corr }}-i_{\text {corr }}\right) / i^{o_{c o r r}}\right] \times 100
$$

Where, $\left(\mathrm{i}_{\text {corr }}\right)$ and $\left(\mathrm{i}_{\text {corr }}\right)$ are respectively the corrosion current density for blank and coated stainless steel with various $\left(\mathrm{WO}_{3}\right) \mathrm{NP}$ coating concentrations at the same temperature. The surface coverage $(\theta)$ of stainless steel by $\left(\mathrm{WO}_{3}\right) \mathrm{NP}$ is estimated by using this relation[9] :

$$
\theta=(\% \mathrm{IE} / 100)
$$

\subsection{Scaning Electron Microscope technique} The SEM - SIGMA HV - Carl Zeiss Scanning Electron Microscope with Bruker Quantax 200 - 


\section{Al-Nahrain Journal of Science}

ANJS, Vol.23 (1), March, 2020, pp. 27 - 34

Z10 EDS Detector was used to investigate the surface morphology of the $\mathrm{WO}_{3}$ nanoparticles.

\section{Results and Discussion}

\subsection{Polarization Measurements}

Figures $1(\mathrm{a}-\mathrm{d})$ illustrate the corrosion polarization plots of stainless steel in sodium chloride solution (3.5\%) for uninhibited and inhibited solution by various concentrations of $\left(\mathrm{WO}_{3}\right) \mathrm{NP}$ coatings at 293, 298,303,308 and 313 K. Electrochemical parameters such as corrosion potentials ( $\left.\mathrm{E}_{\text {corr }}\right)$, cathodic $\left(b_{c}\right)$, and anodic $\left(b_{a}\right)$ Tafel slopes and corrosion current densities ( $i_{\text {corr }}$ ), are tabulated in
Table 1. The data obtained show that the presence of $\left(\mathrm{WO}_{3}\right) \mathrm{NP}$ coating caused an alteration in the $\mathrm{E}_{\text {corr }}$ data of stainless steel and the shifting range is toward more negative values with increasing temperature and less negative values with an increased concentration of coated inhibitor as indicated in Table 1 . This behavior may be attributed to the basis of the decreased corrosion feasibility in the presence of $\left(\mathrm{WO}_{3}\right) \mathrm{NP}$ and also due to increased coating concentration, indicating that the coated $\left(\mathrm{WO}_{3}\right) \mathrm{NP}$ affects anode reaction rather than cathode reaction.
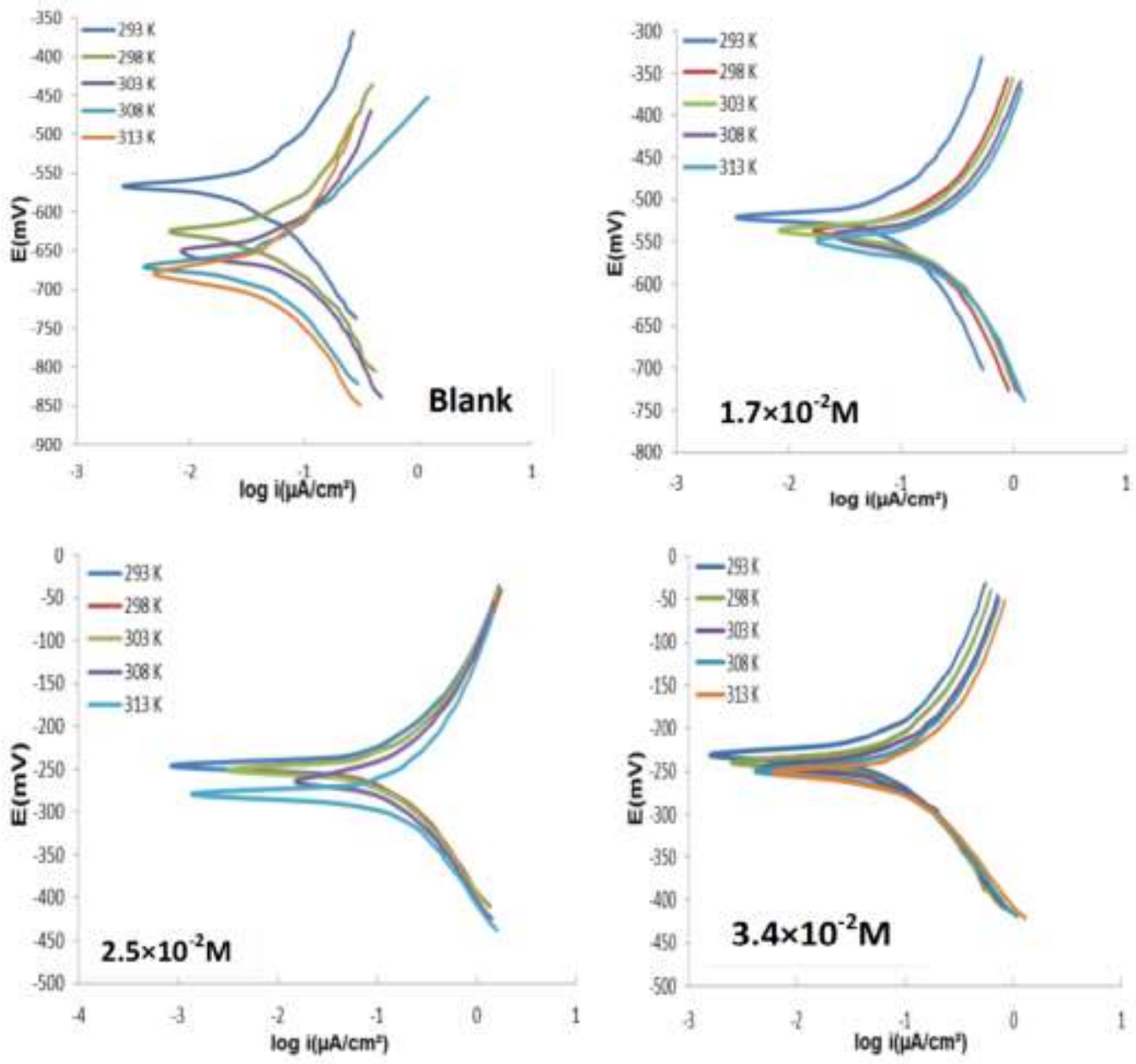

Figure 1. Polarization curves for stainless steel corrosion in 3.5\% sodium chloride solution in the absence and presence of different coated concentrations of tungsten oxide nanoparticles at various temperatures in the range (293-313) $\mathrm{K}$. 


\section{Al-Nahrain Journal of Science}

ANJS, Vol.23 (1), March, 2020, pp. 27 - 34

At a constant $\mathrm{WO}_{3} \mathrm{NP}$ coating concentration, $\mathrm{E}_{\text {corr }}$ were moved toward active values with the rise of temperature. Thus, the increased temperature makes corrosion of stainless steel more convenient as shown in Table 1. On the other hand, the values of the corrosion current density (icorr) at constant tungsten oxide nanoparticles coating concentration were increased with the rise of temperature. Meanwhile, icorr data decreased with increasing tungsten oxide concentration and this behavior may be due to the better corrosion protection of $\mathrm{WO}_{3} \mathrm{NP}$ adsorbed on the surface of steel. Therefore Tafel discussion of $\mathrm{WO}_{3} \mathrm{NP}$ illustrates the restricted mobility of electrolyte ions to the steel surface in saline medium. This is indicative that $\mathrm{WO}_{3} \mathrm{NP}$ coating reflects the remarkable anticorrosion properties for steel alloy [10]. Therefore, Increasing coating $\mathrm{WO}_{3} \mathrm{NP}$ concentration leads to an increase of the protection efficiencies (\%IE) due to good adhesion property of $\mathrm{WO}_{3} \mathrm{NP}$ coating and strong compact adsorbed films which are formed on the surface of the stainless steel with increase of the temperature. This implies the increase in surface coverage $(\theta)$ with increase in the coating concentration. Thus, the maximum inhibition efficiency of $79.66 \%$ was achieved at the highest $\mathrm{WO}_{3} \mathrm{NP}$ coating concentration of $3.4 \times 10^{-2} \mathrm{M}$ and at 313K. Cathodic and anodic Tafel slopes data are changed at all $\mathrm{WO}_{3} \mathrm{NP}$ coating concentrations and temperatures as shown in table 1. These results indicate a change in the charge transfer mechanism to chemical precipitation or to electrochemical desorption the cathodic reactions and also to the variation of the anodic (dissolution) reaction of stainless steel alloy [11].

Table 1. Corrosion parameters of stainless steel in $3.5 \%$ sodium chloride solution in the absence and presence of different coated concentrations $\left(1.7 \times 10^{-2}, 2.5 \times 10^{-2}\right.$ and $\left.3.4 \times 10^{-2}\right) \mathrm{M}$ of tungsten oxide nanoparticles at various temperatures in the range $(293-313) \mathrm{K}$.

\begin{tabular}{|c|c|c|c|c|c|c|c|}
\hline \multirow[t]{2}{*}{$\begin{array}{c}\operatorname{In} \times 10^{2} \\
{[\mathrm{M}]}\end{array}$} & \multirow[t]{2}{*}{$\begin{array}{c}\mathrm{T} \\
{[\mathrm{K}]}\end{array}$} & \multirow[t]{2}{*}{$\begin{array}{l}-\mathrm{E}_{\text {corr }} \\
{[\mathrm{mV}]}\end{array}$} & \multirow[t]{2}{*}{$\begin{array}{c}\mathrm{i}_{\text {corr }} \\
{\left[\mu \mathrm{A} / \mathrm{cm}^{2}\right]}\end{array}$} & \multicolumn{2}{|c|}{$\begin{array}{c}\text { Tafel slope } \\
{[\mathrm{mV} / \mathrm{dec}]}\end{array}$} & \multirow[t]{2}{*}{$\theta$} & \multirow[t]{2}{*}{$\% \mathrm{IE}$} \\
\hline & & & & $-b_{c}$ & $+b_{a}$ & & \\
\hline \multirow{5}{*}{0} & 293 & 567.7 & 48.21 & 123.8 & 89.9 & - & - \\
\hline & 298 & 625.8 & 55.05 & 115.3 & 78.7 & - & - \\
\hline & 303 & 650.8 & 59.47 & 108.8 & 73.6 & - & - \\
\hline & 308 & 669.1 & 65.49 & 151.9 & 92.7 & - & - \\
\hline & 313 & 681.4 & 73.60 & 143.4 & 88.6 & - & - \\
\hline \multirow{5}{*}{1.7} & 293 & 524.4 & 32.39 & 165.9 & 96.5 & 0.328 & 32.81 \\
\hline & 298 & 540.0 & 35.38 & 142.4 & 90.1 & 0.357 & 35.73 \\
\hline & 303 & 545.5 & 37.37 & 123.7 & 76.8 & 0.371 & 37.16 \\
\hline & 308 & 548.6 & 40.68 & 116.4 & 74.4 & 0.378 & 37.88 \\
\hline & 313 & 554.4 & 44.06 & 128.4 & 81.0 & 0.401 & 40.13 \\
\hline \multirow{5}{*}{2.5} & 293 & 246.3 & 21.13 & 60.8 & 44.0 & 0.561 & 56.17 \\
\hline & 298 & 249.1 & 23.12 & 55.5 & 41.6 & 0.580 & 58.00 \\
\hline & 303 & 252.5 & 23.16 & 75.6 & 50.8 & 0.610 & 61.05 \\
\hline & 308 & 263.3 & 23.99 & 88.3 & 56.7 & 0.633 & 63.36 \\
\hline & 313 & 280.1 & 25.73 & 93.0 & 58.2 & 0.650 & 65.04 \\
\hline \multirow{5}{*}{3.4} & 293 & 229.7 & 12.42 & 72.6 & 43.4 & 0.742 & 74.23 \\
\hline & 298 & 238.2 & 13.56 & 76.5 & 44.7 & 0.753 & 75.36 \\
\hline & 303 & 244.2 & 14.04 & 88.6 & 48.5 & 0.763 & 76.39 \\
\hline & 308 & 249.8 & 14.40 & 105.0 & 53.0 & 0.780 & 78.01 \\
\hline & 313 & 251.1 & 14.97 & 109.2 & 55.0 & 0.796 & 79.66 \\
\hline
\end{tabular}




\section{Al-Nahrain Journal of Science}

ANJS, Vol.23 (1), March, 2020, pp. 1-7

\subsection{Corrosion Kinetics}

Temperature dependence of $i_{\text {corr }}$ data was investigated by drawing a log icorr versus $(1 / \mathrm{T})$ plots of blank stainless steel and coated with $\mathrm{WO}_{3} \mathrm{NP}$ in sodium chloride solution in according to Arrhenius equation [12]:

$$
\log \mathrm{i}_{\text {corr. }}=\log \mathrm{A}-\left[\mathrm{E}_{\mathrm{a}} / 2.303 \mathrm{RT}\right]
$$

Where $i_{\text {corr }}$ means the rate of corrosion in temperature (T). $\mathrm{E}_{\mathrm{a}}$ is activation energy and $\mathrm{A}$ is a pre- exponential factor data, respectively, were obtained from the slopes and intersection of Arrhenius diagrams as shown in figure 2. It is clear that the correlation between $\log i_{\text {corr }}$ and $(1 / \mathrm{T})$ in the absence and presence of different concentrations of the coated $\mathrm{WO}_{3} \mathrm{NP}$ fit with straight lines in all cases. The increased $\mathrm{WO}_{3} \mathrm{NP}$ concentration leads to decrease the value of the calculated temperature coefficient $\mathrm{E}_{\mathrm{a}}$ values, showing that the protection efficiency increases as the temperature increase and chemisorption adsorption is more probable [13]. A high value of $\mathrm{E}_{\mathrm{a}}$ is attached to a high value of $\mathrm{A}$ and vice versa is true also, as $\mathrm{E}_{\mathrm{a}}$ is lower for the inhibited solution than for the uninhibited one. This behavior was explained on the basis that $\mathrm{WO}_{3} \mathrm{NP}$ are chemically holed on the surface of the metal, as a result of an increase in the surface area of the metal covered by inhibitor molecules and adsorbed film formation from the reaction product due to an increase in temperature [14,15]. Hence a chemisorption mode of adsorption is more likely. The transition state of Arrhenius equation was used in order to evaluate the enthalpy $\left(\Delta \mathrm{H}^{*}\right)$ and entropy $\left(\Delta \mathrm{S}^{*}\right)$ of activation as indicating from the following [16]:

\section{$\mathrm{i}_{\text {corr. }}=(\mathrm{RT} / \mathrm{Nh}) \exp \left(\Delta \mathrm{S}^{*} / \mathrm{R}\right) \exp \left(-\Delta \mathrm{H}^{*} / \mathrm{RT}\right)$}

where $\mathrm{N}$ and $\mathrm{h}$ are respectively, Avogadro's number and Planck's constant. Figure 3 shows a schematic diagram of lnicorr data versus $1 / T$ data in which values of $\Delta \mathrm{H}^{*}$ and $\Delta \mathrm{S}^{*}$ were determined, respectively, from the slope and intercept, and data obtained are tabulated in table $2 . \Delta \mathrm{H}^{*}$ values are positive and they decrease with increasing the $\left(\mathrm{WO}_{3}\right) \mathrm{NP}$ coated concentration indicating that corrosion process is endothermic [17]. Otherwise, $\Delta \mathrm{S}^{*}$ data is negative and negativity increased by increasing the concentration of coated $\left(\mathrm{WO}_{3}\right) \mathrm{NP}$. The obtained negative values of $\Delta \mathrm{S}^{*}$ revealing that the association step of activated complex is more likely to occur rather than dissociation step in the rate determining step, which means a decrease in disorder [18, 19].

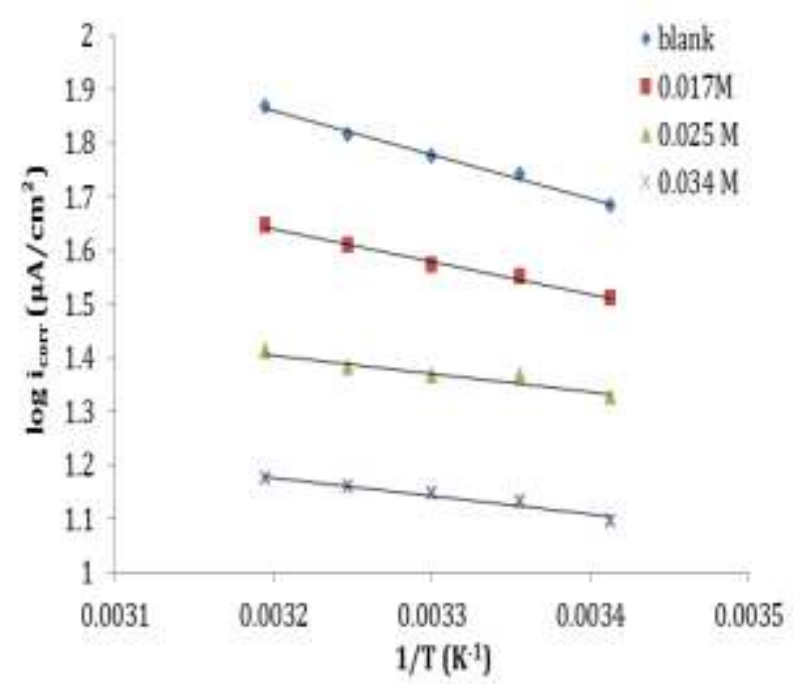

Figure 2. $\log \mathrm{i}_{\text {corr }}$ versus $1 / \mathrm{T}$ of stainless steel corrosion in $3.5 \%$ sodium chloride solution in the absence and presence of different coated concentrations of tungsten oxide nanoparticles

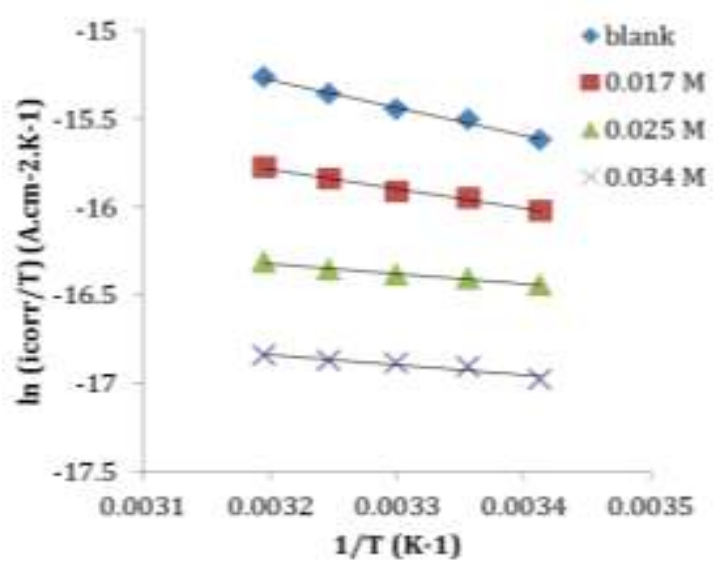

Figure 3. Plots of $\ln \left(\mathrm{i}_{\mathrm{cor} / \mathrm{T}} / \mathrm{T}\right)$ versus $(1 / \mathrm{T})$ for stainless steel in $3.5 \%$ sodium chloride solution in the absence and presence of different coated concentrations of tungsten oxide nanoparticles 


\section{Al-Nahrain Journal of Science}

ANJS, Vol.23 (1), March, 2020, pp. 1-7

Table 2. Activation energy $\left(\mathrm{E}_{\mathrm{a}}\right)$, enthalpy $\left(\Delta \mathrm{H}_{\mathrm{a}}\right)$, and entropy $\left(\Delta \mathrm{S}_{\mathrm{a}}\right)$ of activation for the corrosion of stainless steel in $3.5 \% \mathrm{NaCl}$ solution for blank and coated with various tungsten oxide concentrations.

\begin{tabular}{cccccc}
\hline Con×102 [M] & Ea $[\mathrm{kJ} . \mathrm{mol}-1]$ & $\begin{array}{c}\mathrm{A} \times 10^{28}[\mathrm{molecule} \\
\mathrm{cm}-2 . \mathrm{s}-1]\end{array}$ & $\Delta \mathrm{Ha}[\mathrm{kJ} . \mathrm{mol}-1]$ & $\begin{array}{c}-\Delta \mathrm{Sa} \quad[\mathrm{J} . \mathrm{K}-1 . \mathrm{mol}- \\
1]\end{array}$ \\
\hline- & 15.55 & 1.73 & 13.03 & 282.85 \\
1.7 & 11.5 & 0.22 & 8.98 & 300.02 \\
2.5 & 6.57 & 0.019 & 4.71 & 318.18 \\
3.4 & 6.54 & 0.011 & 4.52 & 323.06 \\
\hline
\end{tabular}

2.3. Scanning Electron Microscopy (SEM)

SEM is a good technique for determining the morphology and particle size of samples. Figures 4 (a-d) illustrate the SEM image of stainless steel sample. The SEM result shows that the surface of the coated alloy is found more smoothly than the uncoated. As well as, $\mathrm{WO}_{3}$ nanoparticles are clearly observed rod. Figure $4 \mathrm{~d}$ shows that there was significantly less damage to the surface of $\mathrm{WO}_{3} \mathrm{NP}$ coated steel by $0.034 \mathrm{M}$. Accordingly, it was concluded that the adsorption film was able to efficiently delay the corrosion of the steel specimen $[20]$.

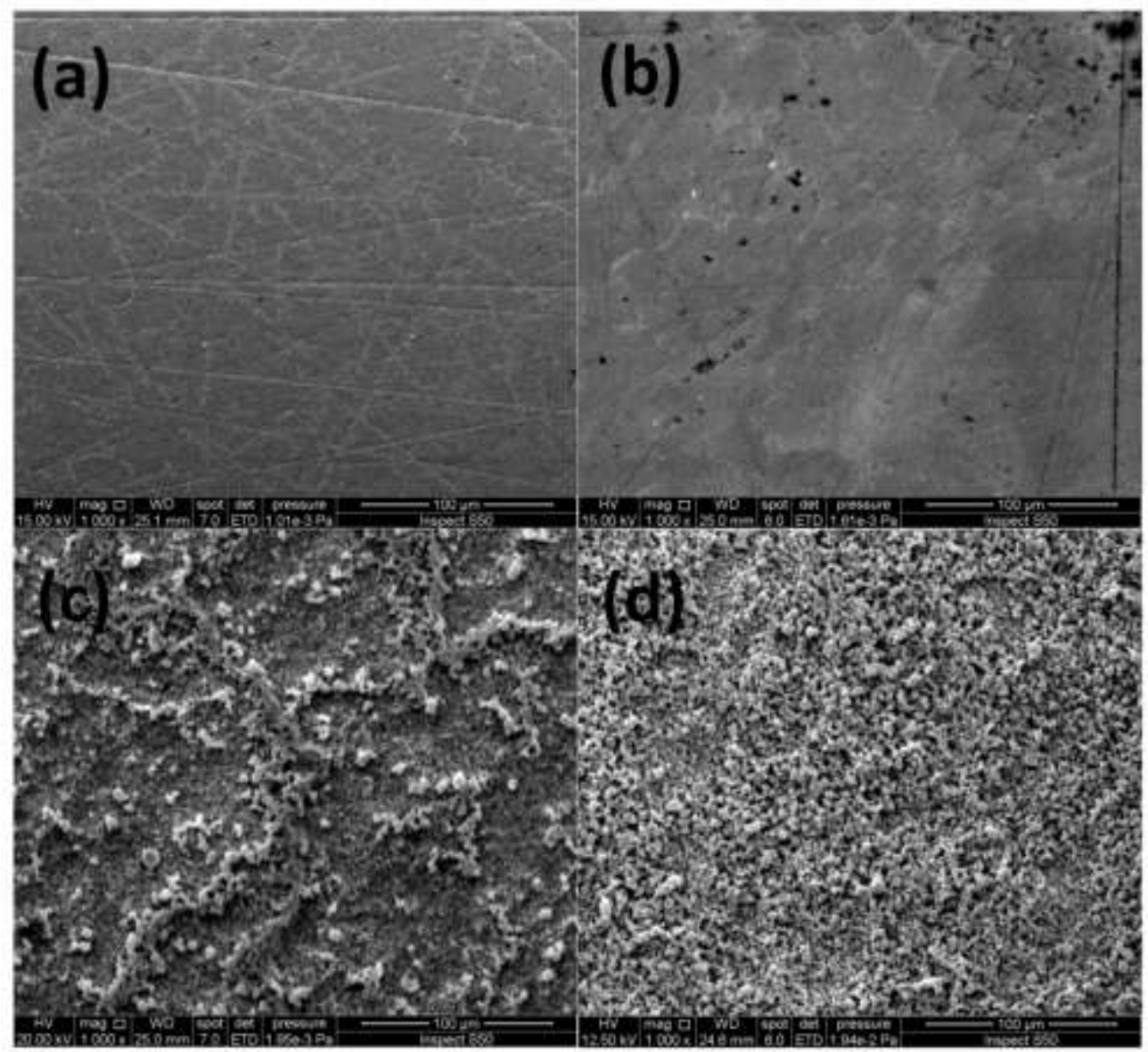

Figure 4. SEM images for stainless steel (a) uncoated (b) immersed in $3.5 \%$ sodium chloride solution for $24 \mathrm{~h}$. (c)coated with WO3 NPs $(0.034 \mathrm{M})$ and (d) immersed in $3.5 \% \mathrm{NaCl}$ for $24 \mathrm{hr}$. after coating. 


\title{
Al-Nahrain Journal of Science
}

\author{
ANJS, Vol.23 (1), March, 2020, pp. 1-7
}

\section{Conclusions}

The anti-corrosion performance of nano-Tungsten oxide was studied by experiments calculations. All coatings concentrations have good corrosion protection performance and their protective efficiencies calculated from the polarization curves are consistent. Moreover, electrophoresis deposited of $\mathrm{WO}_{3} \mathrm{NPs}$ on stainless steel substrate was explained for a thin layer coated for corrosion inhibition studies. The effect of the $\mathrm{WO}_{3} \mathrm{NPs}$ concentration on the coatings morphology and its corrosion behavior were investigated. Based on the obtained results, the use of nanoparticles of tungsten oxide improved the corrosion resistance of coatings. The overall results indicated that corrosion behavior of stainless steel depends on the coated concentration in corrosion media. The nano composite coating that its emulsion $\mathrm{WO}_{3} \mathrm{NPs}$ solution contains $0.034 \mathrm{M}$ nanoparticle has the lowest corrosion rate between all coatings. SEM images showed that before corrosion experiments, the surfaces of stainless steel specimen coated with tungsten oxide nanoparticles was completely smooth and homogeneous by absorption, indicating that the coated nanoparticles had action as a barrier against corrosive environment. Using the tungsten oxide nanoparticles also created a uniform surface.

\section{Acknowledgements}

The authors would like to acknowledge department of chemistry, college of science, Al- Nahrain

University for the support to do this project.

\section{References}

[1] Dickerson, J. H.; Boccaccini, A. R.; "Electrophoretic Deposition of Nanomaterials", Springer, 3-215, 2012.

[2] Djoki, S.; "Electrodeposition and Surface Finishing”, New York, USA, Springer, 1-84, 2014.

[3] Garcia, E. M.; Lins, V. F. C.; Matencio, T.; "Metallic and Oxide Electrodeposition"; Mod. Surf. Eng. Treat., $101-122,2013$.

[4] Palanisamy, K. L.; Devabharathi, V.; Meenakshi, N. S.; "Corrosion Inhibition Studies of Mild Steel With Carrier Oil Stabilized of Iron Oxide Nanoparticles Incorporated Into A Paint"; Int. J. Chemtech. Res. 7, 1661-1664, 2015.

[5] Sajjadnejad, M.; Ghorbani, M.; Afshar, A.; "Microstructure-corrosion resistance relationship of direct and pulse current electrodeposited $\mathrm{Zn}$ $\mathrm{TiO}_{2}$ nanocomposite coatings"; Ceram. Int. 41, 217-224, 2015.

[6] Zeng, Y.B.; Qu, N. S.; Hu, X. Y.; "Preparation and Characterization of Electrodeposited $\mathrm{Ni}^{-} \mathrm{CeO}_{2}$ Nanocomposite Coatings with High Current
Density"; Int. J. Electrochem. Sci. 9, 8145-8154, 2014.

[7] Edelstien, A. S.; Cammarata, R. C.; "Nanomaterials Synthesis, Properties and Applications"; London, UK, IOP Publishing Ltd., 1145-1148, 1996.

[8] Garcia-Ochoa, E.; Guzmán-Jiménez, S. J.; Guadalupe-Hernández, J.; Thangarasu, P.; José, M. V.; Julián, C.; "Benzimidazole ligands in the corrosion inhibition for carbon steel in acid medium: DFT study of its interaction on Fe30 surface"; J. Molec. Struc. 1119, 314-324, 2016.

[9] Kassou1, O.; Galai, M.; Ballakhmima, R. A.; Dkhireche, N.; Rochdi, A.; Ebn-Touhami, M.; Touir, R.; Zarrouk, A.; "Comparative study of low carbon steel corrosion inhibition in $200 \mathrm{ppm}$ $\mathrm{NaCl}$ by amino acid compounds"; Mater. J. Environ. Sci. 6, 1147-1153, 2015.

[10] Salman, T. A.; Najeeb, D. A.; “1, 2(2, 2-dihydroxy Benzelidenamine) Phenyl Complexes as Corrosion Inhibitor for Carbon Steel in Hydrochloric Acid"; Al-Nahrain J. Sci. 21, 13-23, 2018.

[11] Popova, A.; Sokolova, E.; Raicheva, S.; Christov, M.; "AC and DC Study of the Temperature Effect on Mild Steel Corrosion in Acid Media in the Presence of Benzimidazole Derivatives"; Corrosion Sci. 45, 33-58, 2003.

[12] Quraishi, M. A.; Sharma, H. K.; "Corrosion Inhibition Of Mild Steel In Acid Solutions By Some Aromatic Oxadiazoles"; Mater. Chem. Phys. 78, 425-431, 2002.

[13] Salman, T. A.; Al-Azawi, K. F.; Mohammed, I. M.; Al-Baghdadi, Sh. B.; Al-Amiery, A. A.; Gaaz, T. S.; Kadhum, A. H.; "Experimental Studies On Inhibition Of Mild Steel Corrosion By Novel Synthesized Inhibitor Complemented With Quantum Chemical Calculations"; Results In Physics 10, 291, 2018.

[14] Larabi, L.; Harek, Y.; Benali, O.; Ghalem, S.; "Hydrazide Derivatives As Corrosion Inhibitors For Mild Steel In 1 M Hcl”; Progress In Organic Coatings 54, 256-262, 2005.

[15] Mohammad, M.; Saman, Z.; Mosarrat, P.; "LCysteine As Corrosion Inhibitor For Mild Steel In $1 \mathrm{M} \mathrm{Hcl}$ And Synergistic Effect Of Anionic, Cationic and Non-Ionic Surfactants"; Journal of Molecular Liquids 216, 598-607, 2016.

[16] Yadav, M.; Kumar, S.; Tiwari, N.; Bahadur, I.; Ebenso, E. E.; "Experimental and Quantum Chemical Studies of Synthesized Triazine Derivatives as an Efficient Corrosion Inhibitor for N80 Steel in Acidic Medium”, Journal of Molecular Liquids 212, 151-167, 2015.

[17] Odnevall, I.; Leygraf, C.; "Atmospheric Corrosion", ASTM STP 1239; American Society for Testing and Materials, Philadelphia, PA,1995.

[18] Mohamed, G.; Ahmad, B.; Basem, Z.; "Green Corrosion Inhibitor for Carbon Steel in Sulfuric Acid Medium from Calotropis Gigantiea Latex"; 


\section{Al-Nahrain Journal of Science}

ANJS, Vol.23 (1), March, 2020, pp. 1-7

Research on Chemical Intermediates 41, 98859901, 2015.

[19] Zeng, Y. B.; Qu, N. S.; Hu, X. Y.; "Preparation and Characterization of Electrodeposited $\mathrm{Ni}^{-} \mathrm{CeO}_{2}$ Nanocomposite Coatings with High Current Density"; Int. J. Electrochem. Sci. 9, 8145-8154, 2014.
[20] Zheng, H.; Ou, J. Z.; Strano, M. S.; Kaner, R. B.; Mitchell, A.; Kalantar-Zadeh, K.; "Nanostructured Tungsten Oxide: Properties, Synthesis and Applications"; Adv. Funct. Mater. 21, 2175-2196, 2011. 